\title{
63. UN NUEVO HÍBRIDO DEL GÉNERO THYMUS L. (LAMIACEAE)
}

\author{
Antonio DE LA TORRE, María VICEDO, Ma Angeles ALONSO y Joaquín PAYÁ
}

A new hybrid of the genus Thymus L. (Lamiaceae).

Palabras clave. Thymus, híbridos, SE España, Lamiaceae.

Keywords. Thymus, hybrids, SE Spain, Lamiaceae.

Recientemente (De la Torre et al., 1996) han puesto de manifiesto la identidad del taxon Thymus x martinezii Pau ex Martínez, como el híbrido entre las especies Thymus vulgaris L. y Thymus moroderi Pau ex Martínez. Esta afirmación se basaba en el estudio del tipo de Thymus $x$ martinezii, de abundante material de los tres taxones mencionados, así como de Thymus zygis L. subsp. gracilis (Boiss.) R. Morales, que había sido propuesto como posible parental del híbrido, junto a Thymus moroderi, según Morales (1986) y diversos autores posteriores.

Los resultados del citado estudio quedan ahora definitivamente confirmados, al ser hallada una pequeña población mixta de Thymus moroderi y Thymus zygis subsp. gracilis, entre los que convive su híbrido, de aspecto claramente intermedio entre ambos (fig. 1), y que se describe en este trabajo como una nueva notoespecie:

Thymus x herberoi De la Torre, Vicedo, Alonso \& Payá nothosp. nov.

[Thymus moroderi Pau ex Martínez x Thymus zygis L. subsp. gracilis (Boiss.) R. Morales]

Planta inter Th. moroderi et Th. zygidis subsp. gracilidis quasi intermedia. Inflorescentiis infrequenter glomeratis, saepe spiciformibus, bracteis minoribus; floralibus et calycibus brevioribus; corolla alba, a Thymo moroderi differt. Inflorescentiis quam internodiis brevioribus; bracteis quam folia manifeste latioribus; calycibus dentibus labii superioris ciliatis; flores calycis superans, a Thymo zygidi subsp. gracili differt.

Holotypus: Hs, ALICANTE: Elche, Arenales del Sol, habitat inter parentes in dumosis calcareis (Stipo-Sideritidetum leucanthae), 30SYH3756, 110 m, 5-VI-94, leg. A. Almendros \& A. de la Torre, ABH 10006 (fig. 1).

Notoespecie dedicada a la memoria del amigo y amante de la flora alicantina Antonio Esteve Pastor "el herbero".

Caméfito de hasta $30 \mathrm{~cm}$ de altura, ramificado desde la base con los tallos ascendentes. Indumento del tallo denso de cortos pelos retrorsos. Hojas adultas de 4-6 $\mathrm{x}$ 0,5-1 mm, linear-lanceoladas, con margen revoluto, atenuadas en el peciolo, pubescentes, con glándulas esferoidales amarillas tanto en el haz como en el envés; cilios de $1 \mathrm{~mm}$ de longitud en la base, donde el indumento se hace más denso. Inflorescencia espiciforme con verticilastros densos. Brácteas diferenciadas de las hojas caulinares, de 5-7 x 2-3 mm, elípticas con margen algo revoluto, verde-amarillentas a purpúreas; indumento similar al de las hojas. Cáliz de 3-4 mm con tubo de 1,5-2 mm de longitud, tapizado de pelos cortos y glándulas sésiles, amarillas; dientes inferiores lineares de 1,5-2 mm, ciliados; dientes superiores triangulares con 


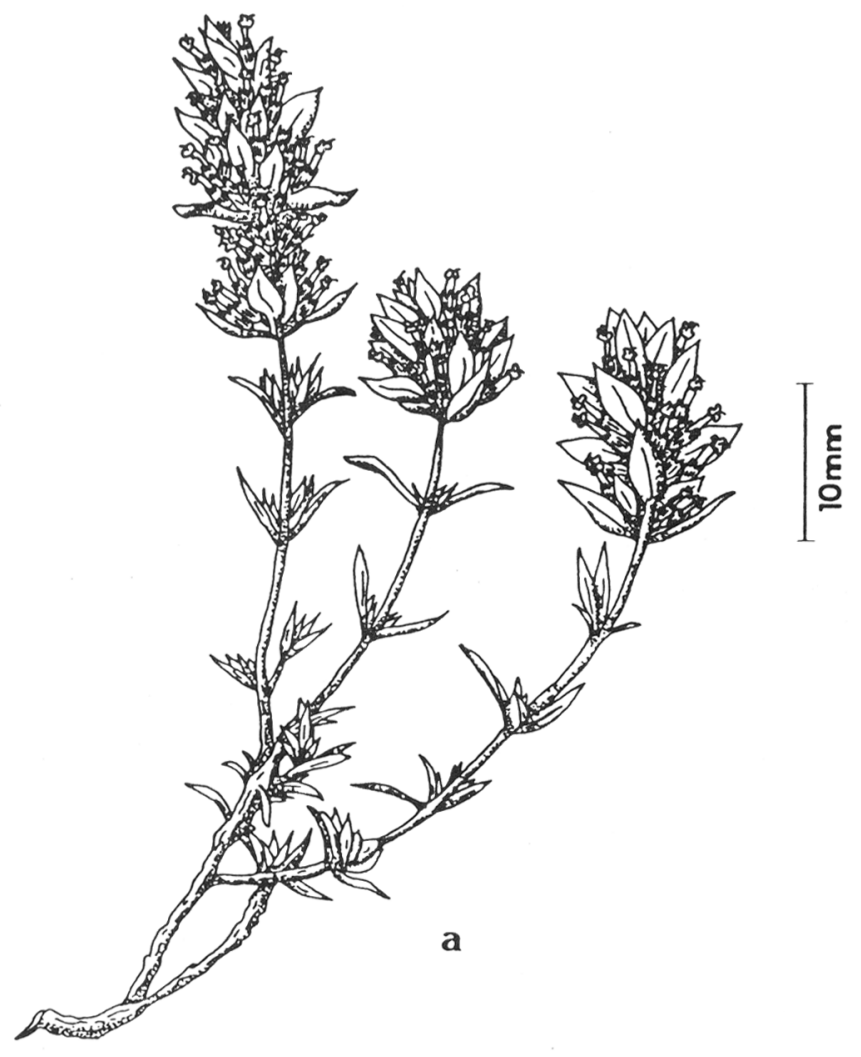

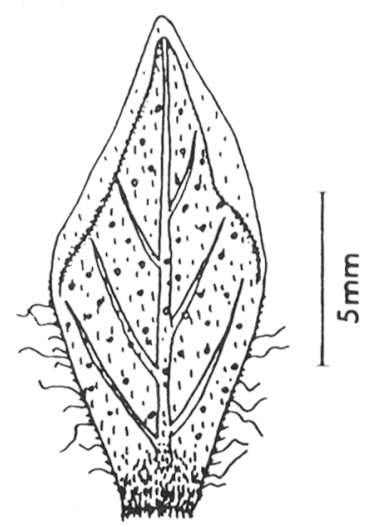

b

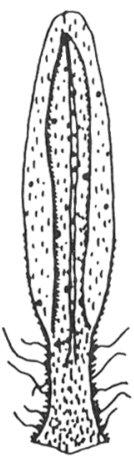

C

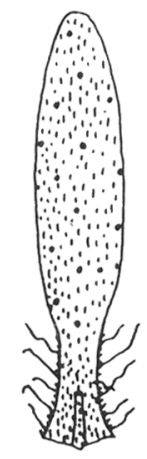

d

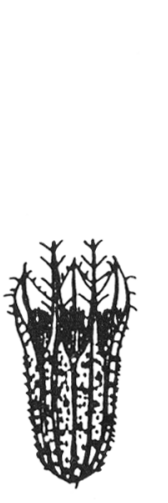

e
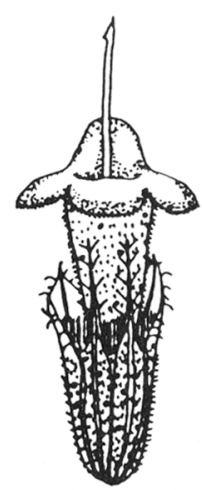

f

Fig. 1.- Thymus x herberoi De la Torre, Vicedo, Alonso \& Payá, nothosp. nov.: a, hábito; b, bráctea; c, envés de la hoja; d, haz de la hoja; e, cáliz; f, flor. Thymus x herberoi De la Torre, Vicedo, Alonso \& Payá, nothosp. nov.: a, habit; b, bract; $c$, lower surface of leaf; $d$, upper surface of leaf; e, calyx; flower. 


\begin{tabular}{lccc}
\hline & T. moroderi & T. x herberoi & $\begin{array}{c}\text { T. zygis subsp. } \\
\text { gracilis }\end{array}$ \\
\hline Cilios en la base de las hojas (si/no) & SI & SI & SI \\
Longitud y anchura de las hojas (mm) & $5.8 \times 0.9$ & $5 \times 0.8$ & $3.9 \times 0.9$ \\
Inflorescencia & Cabezuelas & Verticilastros & Verticilastros \\
& & aproximados & distantes \\
& & & SI \\
Brácteas diferenciadas (si/no) & SI & $6 \times 2.5$ & $3.9 \times 0.9$ \\
Longitud y anchura de las brácteas (mm) & $10.8 \times 6.4$ & A veces & NO \\
Brácteas coloreadas (si/no) & SI & 3.5 & 2.8 \\
Longitud del cáliz (mm) & 6.5 & 1.8 & 1.2 \\
Longitud de los dientes inferiores del cáliz (mm) & 3.3 & SI & NO \\
Cilios en los dientes superiores del cáliz (si/no) & SI & 5.5 & 2.2 \\
Longitud de la corola (mm) & 13.8 & & \\
& & & \\
\hline
\end{tabular}

Tabla 1. Comparación entre los principales caracteres morfológicos. Morphological characters.

cilios cortos. La corola blanca, de 5-6 mm, superando en longitud al tubo del cáliz, con pelos finos y glándulas aplicadas.

En la tabla 1 se recogen las diferencias morfológicas principales entre el híbrido y los taxones parentales.

Difiere de Thymus moroderi por su inflorescencia no capituliforme, sus brácteas de menor tamaño y color menos intenso; flor de menor tamaño y corola blanca.

De Thymus zygis subsp. gracilis difiere por su inflorescencia en verticilastros no distantes; sus brácteas diferenciadas de las hojas caulinares, dientes superiores del cáliz ciliados, y corolas superando en longitud al tubo del caliz.

AGRADECIMIENTOS. Deseamos mostrar nuestro agradecimiento al Dr. Diego Rivera (Universidad de Murcia), por sus observaciones.

\section{BIBLIOGRAFÍA}

DE LA TORRE, A., M. VICEDO y M.A. ALONSO -1996- On the identity of Thymus $x$ martinezii Pau ex Martínez (Lamiaceae), an endemic hybrid of the southeastern Iberian Peninsula. Flora Mediterranea 6: 23-29.

MORALES, R. -1986- Taxonomía de los géneros Thymus (excluida la sección Serpyllum) y Thymbra en la Península Ibérica. Ruizia 3: 1 324.

Aceptado para su publicación en Septiembre de 1997

Dirección de los autores. Departamento de Ciencias Ambientales y Recursos Naturales (Botánica), Universidad de Alicante. Apdo. 99. E-03080 Alicante. E-mail: torre@minos.carn.ua.es. 